\title{
Behavioural Experiments in Cognitive Therapy for Posttraumatic Stress Disorder: Why, When, and How?
}

\author{
Hannah Murray ${ }^{a}$ Sharif El-Leithy ${ }^{b}$ \\ ${ }^{a}$ Oxford Centre for Anxiety Disorders and Trauma, University of Oxford, and Oxford Health NHS Foundation Trust, \\ Oxford, UK; ${ }^{\text {b}}$ Traumatic Stress Service, South-West London \& St George's NHS Trust, London, UK
}

\section{Keywords}

Posttraumatic stress disorder - Trauma - Cognitive therapy · Cognitive behavioural therapy

\section{Abstract}

Behavioural experiments are an integral component of cognitive therapy (CT) for posttraumatic stress disorder (PTSD), but they can be overlooked due to practical constraints and therapist concerns. Here we describe why behavioural experiments are an important part of $\mathrm{CT}$, where they fit into different elements of treatment for PTSD, how to design and implement effective experiments including coping with unexpected outcomes, and how to incorporate behavioural experiments when therapy is delivered remotely. Clinical case examples are used to illustrate a range of idiosyncratic and creative behavioural experiments. @ 2020 The Author(s)

Published by S. Karger AG, Basel
\end{abstract}

\section{Verhaltensexperimente in der kognitiven Therapie von posttraumatischer Belastungsstörung: wieso, wann und wie?}

\section{Schlüsselwörter}

Posttraumatische Belastungsstörung · Trauma ·

Kognitive Therapie $\cdot$ Kognitive Verhaltenstherapie

\section{Zusammenfassung}

Verhaltensexperimente sind eine integrale Komponente der kognitiven Therapie von posttraumatischer Belas- tungsstörung (PTBS), sie können aber aufgrund praktischer Beschränkungen und Bedenken des Therapeuten übersehnen werden. Im Folgenden beschreiben wir, warum Verhaltensexperimente ein wichtiger Bestandteil der kognitiven Therapie sind, an welcher Stelle sie in verschiedene Elemente der Behandlung von PTBS hineinpassen, wie effektive Experimente einschließlich des Umgangs mit unerwarteten Ergebnissen entwickelt und implementiert werden können und wie Verhaltensexperimente eingebaut werden können, wenn die Therapie aus der Ferne erfolgt. Klinische Fallbeispiele werden verwendet, um die Bandbreite idiosynkratischer und kreativer Verhaltensexperimente zu zeigen. $\quad$ O 2020 The Author(s) Published by S. Karger AG, Basel

\section{Introduction}

Behavioural experiments are a core component of cognitive therapy (CT) for posttraumatic stress disorder (CTPTSD) [Ehlers, 1999; Ehlers and Clark, 2000], a traumafocused cognitive behavioural therapy with demonstrated efficacy in randomised controlled trials [Ehlers et al., 2003, 2005,2014 ], and in routine clinical practice [Ehlers et al., 2013]. When well designed and implemented, behavioural experiments are a powerful way to help clients evaluate and modify beliefs about a trauma and its consequences. They can provide new information with which to update memories, help promote alternative coping strategies, and support and enhance various tasks in therapy. Importantly, behavioural experiments can be integral to overcoming common obstacles in PTSD treatment. original publisher. 
Some clinicians feel anxious about, and may avoid, exposure components of trauma-focused therapies [e.g., Becker et al., 2004]. In our experience, most cognitive behavioural therapists know the advantages of behavioural experiments, but they are often neglected in therapy or left to the client to do for homework. Therapists sometimes face practical obstacles such as limited session time and believe that behavioural experiments require too much time to plan and carry out. Others are concerned about the potential for unpredictable or unintended outcomes to experiments. Omitting this effective component of treatment may contribute to poorer outcomes for PTSD clients, contributing to the "research-practice gap" between the high recovery rates demonstrated in randomised controlled controls and those achieved in routine clinical practice [Murray, 2017].

In this article, we explain the different functions of behavioural experiments in CT-PTSD, describe and illustrate different types of behavioural experiments, and provide some practical guidelines on how to design and carry out effective behavioural experiments. We hope this will provide inspiration and encouragement for therapists to prioritise creative and powerful behavioural experiments in their practice.

\section{Why to Use Behavioural Experiments in CT}

Behavioural experiments lie at the heart of therapeutic change in $\mathrm{CT}$ and encompass a wide range of experiential tasks that have the primary goal of learning something new [Bennett-Levy et al., 2004]. They have various functions, most commonly to test aspects of a case formulation, to demonstrate the effects of an unhelpful cognitive or behavioural strategy, to test the validity of negative beliefs, and to construct and strengthen adaptive beliefs.

Behavioural experiments work alongside other cognitive change techniques in CT. For example, when a negative belief has been identified, the therapist may use guided discovery techniques to explore the belief and to help the client consider alternative perspectives. In some cases, discussion techniques such as thought challenging, psychoeducation, and identification of thinking errors are sufficient to effect cognitive change. However, very often these techniques raise questions that then need to be tested, using a behavioural experiment.

Johanna believed that she would be attacked again if she went out at night. Her therapist helped her consider evidence for and against this belief, and to look at the probability of a further attack occurring. Johanna concluded that her chances of being attacked again might be lower than she feared, but she continued to feel anxious about the possibility. Together with her therapist, Johanna planned a behavioural experiment where she walked home from her sister's house alone. She was not attacked and her rating of the likelihood of a further attack decreased. She began to feel safer.
This case illustrates some of the advantages of behavioural experiments. Experiential techniques have the potential to correct head-heart lag, the common tendency for belief change to happen intellectually, but not to be felt emotionally. Experiencing evidence for a new belief is often more powerful and more memorable than just discussing it [Engelkamp, 1998]. When we ask our clients what they remember from our sessions at the end of treatment, it is often times when we did something actively rather than just talked. Another advantage of behavioural experiments is that they activate the cognitions and behaviours that we want to work on, rendering them more readily amenable to change. They can also help us as therapists to spot subtle safety-seeking behaviours (behaviours intended to prevent a feared outcome) that the patient is unaware of because they are so habitual, or cognitions that are not easy to access because they are only activated situationally.

The importance of behavioural experiments in effecting change has also been highlighted in contemporary accounts of PTSD emerging from computational psychiatry and neuroscience, such as the predictive processing account of PTSD [Kube et al., 2020]. This approach explains how a traumatic event influences the perceptual system, with the life-threatening significance of the experience creating a strong "prior probability" of a threatening meaning being selected again, even if a new situation does not exactly match the previous experience. In other words, objectively safe situations may feel highly threatening and will understandably be avoided. Additionally, new experiences, such as a safe encounter with a previously threatening stimulus, may not automatically correct this bias as strongly held prior beliefs can override disconfirmatory information [Kube and Rozenkrantz, 2020]. Behavioural experiments are considered an important therapeutic tool in this model, with clients encouraged to experience that feared predictions do not eventuate when the situation is entered.

There is an important difference between behavioural experiments and traditional exposure therapy. Behavioural experiments aim to test a belief or prediction and to discover something new. Exposure therapy originates from a behavioural model of habituation - the idea that anxiety decreases over time when someone is exposed to feared stimuli. It may be that some habituation occurs when we do a behavioural experiment, but this is not the goal; we are aiming to test a cognition. We do not need to work up a hierarchy of feared situations or remain in the situation until the subjective units of distress drop to a certain level (common techniques in exposure therapy). Instead, we select the situation or task which provides the best test of a particular belief and use it to learn something new, then remain in it only long enough to "prove the point" or "answer the question." Behavioural experi- 
Table 1. Overview of CT-PTSD treatment techniques, related appraisals, and behavioural experiments

\begin{tabular}{lll}
\hline CT-PTSD treatment technique $\quad$ Example appraisals & Behavioural experiments
\end{tabular}

Drop maintaining cognitive or "If I don't push the memories away, I will go mad/ behavioural strategies be overwhelmed/my symptoms will get worse"
"I need to be aware of my surroundings constantly in case I am attacked again"
Thought suppression (white bear) experiment Testing effects of not pushing memories away

Increase hypervigilance in a safe environment to test effect on anxiety

Drop hypervigilance in feared environments to test likelihood of feared outcome

"If I don't check my door is locked, someone will Increase and then decrease level of checking to assess effect on break in"

"I can't get to sleep without alcohol" anxiety and feared outcome

\begin{tabular}{lll} 
& "I can't get to sleep without alcohol" & $\begin{array}{l}\text { Keep a record of sleeping hours on nights when alcohol is } \\
\text { drunk and not drunk }\end{array}$ \\
\hline Reclaiming your life & "I won't enjoy myself" & Rate mood before and after activity
\end{tabular}

Reclaiming your life

"I won't enjoy myself" Rate mood before and after activity

"Something bad will happen if I let myself be happy" Plan an enjoyable activity and then monitor serious negative events within a brief time frame after the activity

"My hands will shake and people will stare at me" Therapist and then client deliberately shakes in public and observes responses from other people

Addressing appraisals linked to "Other people will think the trauma was my fault" Survey of other people's opinions of client's responsibility guilt, shame, and anger

"My reaction at the time of the trauma was Research different responses to trauma; speak to experts abnormal"

"If I let go of the anger, I will be overwhelmed by other feelings"

"If I allow myself to feel something, I will permanently lose control of my emotions"

Addressing beliefs about safety "Driving on the motorway is dangerous"

Reduce angry rumination and measure effects on other emotions

Watch a sad movie and measure how long negative emotions last

Watch a motorway for an hour and record the number of accidents

Drive on a motorway as a passenger or driver to test whether another accident occurs

"People will attack me if I disagree with them" Make a complaint in a shop and see whether I am attacked

"Many young people carry knives"

Research statistics about knife carrying; speak to an expert; survey a group of young people

Addressing beliefs following physical injury

"If I exercise, my pain will be unbearable"

Try different types of exercise and record level and longevity of pain and mood before and afterwards

"People will attack me if they see I am disabled" Research and survey attitudes to disability and crime exposure Tell people or display disability to test whether attacks occur

"Women will find me unattractive because of my scars"

Survey on scars and attractiveness

Include photo where scars are visible on dating profile and record response

Updating the trauma memory "If I talk about the trauma in detail, my PTSD symptoms will get worse"

Give a brief account of the trauma and measure symptoms before, after, and over the following days

"If my therapist knows what I did, they will reject $\quad \begin{aligned} & \text { Ask therapist about the type of work they do and the different } \\ & \text { things they hear }\end{aligned}$
me"
me"

things they hear

Disclose part of the trauma and ask the therapist for feedback on their reaction

"There's no point working on the memory; my symptoms will never improve"

Watch client testimony DVD to hear about other people's experiences

Review questionnaire scores with my therapist every week to see if symptoms are improving

Returning to the scene of the "If I go back to the site, my attacker will be there"

Look at the site on Google Street View first to see if attacker if visible

Go back with therapist to look for attacker

"The scene will look the same as at the time of the trauma; there will be blood and glass"

At the site of the trauma, look for traces of blood and glass; look for differences between "then" and "now"

"Something bad happened during the trauma that I

don't remember"

At the scene, reconstruct the trauma and look for clues as to what may have occurred during memory gaps

CT-PTSD, cognitive therapy for posttraumatic stress disorder; PTSD, posttraumatic stress disorder. 
ments can therefore be faster and more cost-effective than exposure therapy, and quicker results can make them less aversive to both clients and therapists.

Recent research into the mechanisms underlying exposure therapies has highlighted the importance of inhibitory learning as opposed to habituation, to reduce the possibility of the fear response re-emerging after a period of time, in different contexts or following a further trauma [e.g., Craske et al., 2014]. One of the ways to enhance inhibitory learning is via expectancy violation, where the goal of exposure is not merely to habituate to a feared situation or object, but to learn that predictions of a feared outcome do not materialise. Learning has also shown to be optimised in other ways, including by dropping safety-seeking behaviours and varying the context of exposures [Craske et al., 2014]. Thus, as our understanding of how to maximise the effectiveness of exposure therapies increases, a more nuanced approach has emerged, which corresponds closely with the behavioural experiment in CT.

\section{When to Use Behavioural Experiments in CT-PTSD}

Ehlers and Clark's [2000] cognitive model of PTSD proposes that a traumatic event has been processed in a way that leads to a sense of current threat. For example, if a trauma leads an individual to believe that the world is more dangerous than they realised and they are less able to cope with unexpected events than they previously believed, they are likely to feel under threat and more likely to engage in cognitive and behavioural strategies to keep themselves safe. These strategies inadvertently maintain PTSD by preventing disconfirmation of their beliefs. For example, they may engage with extra checking behaviours in order to feel safe, which prevents them from learning that the trauma was a one-off and the world is no more dangerous than it was before the trauma. Additionally, Ehlers and Clark [2000] proposed that trauma memories are disjointed and poorly integrated into autobiographical memory and therefore easily triggered, leading to intrusive symptoms of PTSD such as flashbacks. The understandable tendency for sufferers of PTSD to avoid thinking and talking about their trauma maintains this problem as the trauma memory remains in its original state and is not fully processed in autobiographical memory.

The aims of CT-PTSD are therefore to elaborate and integrate the trauma memory, to identify and modify appraisals of the trauma or its sequelae which maintain the current sense of threat, and to drop any problematic behavioural and cognitive strategies. As we will discuss in this section, behavioural experiments are used as part of achieving these aims. Table 1 shows an overview of the main treatment techniques utilised in CT-PTSD, related appraisals, and possible behavioural experiments, which are described further below.

\section{Testing the Effects of Coping Strategies}

An early intervention in CT-PTSD is often to help the client evaluate, and then modify or drop, cognitive or behavioural coping strategies. These coping strategies underlie some of the core symptoms of PTSD, namely avoidance and hypervigilance. Beliefs maintain these behaviours, e.g., "if I let myself think about the trauma, my symptoms will get worse," which are an important component in the maintenance of PTSD as they inadvertently worsen symptoms. For example, strategies such as thought suppression tend to increase the number of intrusions that people have due to the "rebound effect," and increased vigilance (increased awareness and scanning for possible danger) tends to make people feel more unsafe because they become aware of triggering cues in their environment. Rumination can both trigger intrusive memories and maintain problematic appraisals.

Behavioural experiments are a useful way of testing the effects of coping strategies on symptoms and the beliefs which underlie them. The basic approach is to first observe the coping strategies that a client uses (this sometimes entails going with them into a situation where their sense of threat is triggered, such as a busy place). The next step is to test the impact of a coping strategy by increasing and then decreasing it, and observing the effect on particular symptoms.

Below are some "off-the-shelf" examples of this type of behavioural experiment:

Thought Suppression. Intrusive memories of the trauma are a core symptom on PTSD. A variant of the "white bear" paradigm [Wegner et al., 1987] is a good way to demonstrate the effects of thought suppression. Clients are asked to try as hard as possible not to think about a white bear (or green rabbit or equivalent) for a few minutes, and generally discover that trying not to think of something actually makes it come to mind more often (the so-called "rebound effect"). This can be followed up with a homework experiment where, instead of trying to suppress trauma memories, the client allows them to come and go, like a train coming into a station and then leaving again, and observe what happens [Ehlers, 1999; Ehlers and Clark, 2000].

Rumination. Clients are asked to vary the amount they ruminate and to measure the effect $\mathrm{n}$ their PTSD intrusions. For example, they are asked to ruminate as much as possible about their usual area of worry for the first half of the week, and then to ruminate as little as possible for the second half of the week.

Hypervigilance. The therapist and client choose a situation where the client does not usually feel anxious. For 
Table 2. Paul's behavioural experiment record form

\begin{tabular}{|c|c|c|c|c|}
\hline $\begin{array}{l}\text { Situation/trigger } \\
\text { Belief/emotion } \\
\text { Memory } \\
\text { Coping behaviour }\end{array}$ & $\begin{array}{l}\text { Prediction: } \\
\text { how likely }(0-100 \%)\end{array}$ & Experiment & $\begin{array}{l}\text { What actually happened? } \\
\text { Was your prediction } \\
\text { correct? }\end{array}$ & $\begin{array}{l}\text { What did you learn? } \\
\text { How can you take this forward? }\end{array}$ \\
\hline $\begin{array}{l}\text { Disagreements/being pulled over by } \\
\text { the police } \\
\text { I have to challenge others or I will feel } \\
\text { weak and useless afterwards (anger/ } \\
\text { humiliation) } \\
\text { Hotspot - memory of the police raid } \\
\text { Act aggressively and confront }\end{array}$ & $\begin{array}{l}\text { If I let others mistreat } \\
\text { me or don't argue } \\
\text { with the police, then I } \\
\text { will brood so much } \\
\text { afterwards it will ruin } \\
\text { my day }(100 \%)\end{array}$ & $\begin{array}{l}\text { Do the opposite - } \\
\text { act just like the } \\
\text { Dalai Lama } \\
\text { (a model of } \\
\text { acceptance) - see } \\
\text { how long I brood } \\
\text { afterwards }\end{array}$ & $\begin{array}{l}\text { When I went into "full } \\
\text { compliance mode" they } \\
\text { were less unpleasant, I } \\
\text { just walked away and got } \\
\text { on with my day, I didn't } \\
\text { feel weak or brood } \\
\text { afterwards }\end{array}$ & $\begin{array}{l}\text { Using "compliance mode" helps } \\
\text { diffuse some situations that would } \\
\text { otherwise ruin my day and reduces } \\
\text { subsequent brooding; I can use this } \\
\text { strategy to defeat provocation, } \\
\text { which makes me feels stronger } \\
(80 \%)\end{array}$ \\
\hline
\end{tabular}

example, if their trauma did not involve a traffic accident, then a busy road is a good option, although this can also be done in the therapist's office. They are then asked to focus as much as possible on the potential dangers in the situation. On the road, this might include near misses, poor driving, dangers to cyclists and pedestrians, and so on. In the therapist's office, the client is asked to look out for any potential risks, possible escape routes, etc. The effect of this extra vigilance on the client's sense of threat is then measured, often revealing that the more we look for danger, the more unsafe we feel.

Checking. Clients who engage in unnecessary checking behaviours, such as locks, windows, and doors, are asked to temporarily increase this behaviour and then decrease it, measuring the effect on their anxiety.

Sleep Avoidance. Many people put off going to bed for fear of having nightmares, which leads to the additional symptom of fatigue. A potential experiment involves going to bed as late as usual for half of the week, and then at a pre-agreed earlier time for the second half of the week and observing the effect on nightmare frequency, sleep quality, and fatigue.

Drugs and/or Alcohol. Unlike other coping strategies, it can be unsafe to use experiments which involve increasing their use intentionally, so experiments are instead conducted on the effects of decreasing use on target symptoms and contrasting with their naturalistic use. People often use drugs and/or alcohol to manage symptoms of PTSD, such as to help them get to sleep, to relax, or to escape unpleasant intrusive images. Experiments may involve, therefore, measuring these symptoms on days where a client uses the substances and on days where they do not. Dropping the use of substances can also be used to test other predictions, e.g., "I won't have fun if I'm not drinking" or "I need to take Valium before I can use a train." For some individuals, especially those who are dependent on substances, significant extra work may be needed to enable such experiments.
These behavioural experiments will be relevant to many clients. For others, we may design more idiosyncratic experiments to address specific coping strategies.

Paul developed PTSD after his shared house had been raided by armed police who arrested his housemate. The memory was triggered when he saw police officers and he believed that if he did not challenge them he would feel weak and humiliated. He tended to therefore act aggressively and confront the police if they approached him, which they started to do with more frequency now that he was known to them. Together with his therapist, Paul planned an experiment they code-named "Operation Dalai Lama." Instead of confronting the police, Paul would do the opposite and exude the peace and tranquillity of the Dalai Lama, politely answering every question and complying with their requests. He would monitor how long he brooded about the encounter afterwards. Paul discovered that the strategy meant that the police were less unpleasant towards him and left him alone more to get on with his day. To his surprise, he did not feel weak and humiliated afterwards, brooded less on the encounter, and felt more in control of his interactions with the police. His behavioural experiment record form is shown in Table 2.

\section{Testing Beliefs about Reclaiming Your Life}

An important therapeutic task in CT-PTSD, which begins in session one and continues throughout treatment, is to help clients begin the process of "reclaiming your life" after trauma, which includes identifying previously valued activities which have been neglected and helping the client to gradually re-engage in them. Reclaiming your life tasks help the client reconnect with their pretrauma self and to challenge beliefs about permanent change. It is not uncommon for blocking beliefs to obstruct this process, and behavioural experiments are a useful means of addressing these. For example:

- "I won't enjoy myself, it won't make me feel better." To test this, the client can do something they used to enjoy, rating their predicted enjoyment level beforehand and their actual enjoyment level afterwards.

- "I'm too jumpy, people will notice and think I am weird." Much like social anxiety behavioural experiments [e.g., Clark, 2005], the therapist can model being jumpy in a public place like a local café, and the 
client can observe how people react before trying it themselves.

- "I can't be bothered, I don't have the energy." Setting a small task and rating energy levels before and after can test this belief. Many clients with PTSD are also depressed and may struggle to do this alone, so a cotherapist/family member can be asked to help. Alternatively, the therapist and client can try a brief activity in session, such as going for a short walk to test the effect on energy levels.

- "I can never be the person I used to be." To test this, the therapist asks the client to identify some of the activities that used to characterise them as an individual. These can be gradually attempted, with the client rating their sense of permanent change before and after the activity.

Cathy had experienced multiple traumas in her lifetime and had developed the belief that bad things happened when she let herself be happy. Reclaiming your life was therefore a difficult therapeutic task for Cathy. Cathy's therapist suggested that she experiment with doing an enjoyable activity (Cathy chose watching her favourite film while eating ice cream) to test her prediction that something bad would happen if she felt happy. They agreed a time frame $(24 \mathrm{~h})$ and a level of severity that the bad event would need to reach for it to "count." When no significant negative events happened after the experiment, Cathy's belief rating decreased and she agreed to continue engaging in enjoyable activities.

\section{Generating Data to Test Appraisals about Guilt, \\ Shame, and Anger}

An important part of CT-PTSD is to identify and test the excessively negative appraisals about the trauma which are driving the sense of current threat and other common emotions such as shame, guilt, and anger, which are central to the experience of PTSD. In DSM-5, these types of strong, negative appraisals are considered part of the diagnosis of PTSD and are crucial to understanding an individual's distress following a trauma. Such appraisals are idiosyncratic, and behavioural experiments are therefore often highly individualised to test them. Useful techniques include finding ways to gather information about a belief, such as through internet searches, books, and interviewing experts. Here are some examples from our clinical practice:

Derek saw his wife being struck by a car as she crossed the road to meet him. Derek believed that he should have been able to push his wife out of the way of the oncoming car. To test this, he and his therapist returned to the scene of the trauma and measured the distance between Derek and his wife at the time of the accident, and the distance to where they first saw the car. Given the speed that the car had approached, Derek realised it would have been physically impossible for him to get to his wife in time.

Samira experienced a traumatic birth during which she nearly died. She found it difficult to feel emotionally connected to her new baby in the following weeks and felt guilty, believing that she was a terrible mother. To address this, Samira sought information about the experiences of other women. She read a book called "From here to maternity" by Ann Oakley who had interviewed lots of new mothers. She also made an anonymous survey to put on a mother's group on Facebook to see whether anyone else had an experience similar to hers. Samira found evidence that some other mothers had not had an immediate sense of connection with their new baby, especially when the birth had been difficult.

Patience experienced intense shaking throughout her body when she came round from an operation and believed that she had been mistreated and left to die. To find out more about her reaction, her therapist helped her research common reactions after a general anaesthetic by reading the frequently asked questions section of the Royal College of Anaesthetists website. They also arranged a phone call with an anaesthetist from the local hospital who was able to answer Patience's questions about her reaction. Patience learnt that shaking is quite common after an anaesthetic and was not a sign that she was in danger. She had not been left alone, there was a nurse monitoring her in the recovery room.

George experienced a trauma during his work as a firefighter when he had to recover the body of a child after a house fire. He broke down in tears in front of his colleagues and was told to go home to rest. He was embarrassed about his reaction, as he believed that a "true professional" would not have shown emotion. He also had a belief that "real men" do not cry. George's therapist asked him for an example of "real men" and "true professionals" and George decided that soldiers were a good example of this. To test whether soldiers ever cried, his therapist searched for images of soldiers crying on Google. To George's surprise, there were several million photos of soldiers crying. The photos often seemed to be taken at funerals or where soldiers had just experienced a difficult battle. George concluded that even "real men" and "true professionals" cried sometimes, especially after a loss, and that his reaction had been acceptable.

Surveys are a particularly useful tool to gather further information about a belief. Appraisals linked to guilt and shame are often maintained by unwillingness to disclose an aspect of the trauma to others and to learn what their reaction would be. Surveys can be conducted anonymously to gain a range of perspectives on a client's beliefs. Questions are designed with the client. We find it helpful to ask both fixed questions, which produce quantitative results, and open-ended questions, which provide qualitative information.

Eilidh was raped after she went home with a man after their first date. She believed that she was responsible for the rape because she should not have gone home with a man she barely knew, and thought other people would say the same if they knew what had happened. Eilidh and her therapist set up a survey using an online tool. They briefly described the scenario and then asked, "How much was the woman in this scenario to blame for the rape? (0$100 \%)$," "How much was the man to blame? (0-100\%)," "Please explain your answers," and "What would you say to this woman if you met her?" Most people allocated all of the blame to the man. Others gave Eilidh a small amount of blame (on average 10\%) and commented that it was not sensible to go home with a virtual stranger, but that the woman still did not deserve to be raped and was only guilty of being a little too trusting. Eilidh had predicted much higher ratings of blame to be attributed to her. She found many of the comments helpful as most people were sympathetic and supportive. 
For some clients it is the fear of emotion, rather than the emotion itself, which is the required target for treatment, as emotional suppression will perpetuate the maintenance of PTSD and underlie symptoms such as emotional numbing and disconnectedness from others. In these examples, behavioural experiments often include testing the effects of exposure to emotion, e.g., watching a sad movie and testing the tolerability and longevity of the emotional reaction.

\section{Testing Beliefs about Safety and Safety-Seeking \\ Behaviours}

Most people with PTSD engage in excessive behaviours to keep themselves safe. As well as the direct effect of these behaviours on increasing the symptoms of PTSD, safety-seeking behaviours also prevent beliefs about lack of safety from being disconfirmed. For example, someone with PTSD following a car crash may avoid driving or take extra precautions when doing so. They therefore never learn whether another crash would have occurred without these safety-seeking behaviours. Behavioural experiments around safety therefore involve testing a feared situation without using safety-seeking behaviours to address beliefs such as "my behaviours protect me from being in another accident."

It is important here for the therapist to remind the patient to use the "then versus now" trigger discrimination if intrusive memories are triggered during the behavioural experiment. This technique includes the identification on triggers to trauma memories and their intentional presentation, during which the client is encouraged to focus on what is different between "then" (the trauma) and "now" (the reminder). This "then versus now" discrimination technique can be practised in session and for homework while deliberately introducing the trigger (for more information and training videos demonstrating this technique, see www.oxcadatresources.com). Using "then versus now" during a behavioural experiment means that clients can process the situation rather than evaluate its risk from the content of the memories.

Here are a few examples from our practice:

Quinton had been stabbed in a random attack by members of a gang. He avoided groups of young people afterwards for fear of being attacked again. To test this fear, Quinton and his therapist went to a local college at around 4 p.m. when the students were coming out. They approached a group of young people and asked for directions to the nearest station. To his surprise, the students were helpful and polite.

Alicia was in an accident where a nightclub balcony collapsed, injuring many people. She avoided structures which felt unstable such as lifts, pedestrian bridges, and fire escape stairs. With her therapist, Alicia went to a local railway station and stood on the pedestrian bridge. With encouragement from her therapist, Alicia was able to let go of the handrail and even to jump up and down a few times to show herself that it was not going to collapse.
Teri was sexually assaulted after her drink had been spiked. After this, she avoided drinking anything except drinks which were sealed when she got them. Teri agreed for her therapist to pour her a glass of water out of her view, and drank it, to test her fear that she might be spiked again. They then visited a local café and ordered coffees which were made without Teri watching.

\section{Beliefs following Physical Injury}

Many of our clients have beliefs that they have permanently changed in some way after a trauma. This often refers to a sense that they have or their lives have irreversibly changed for the worse. In some cases, there have been genuine physical changes such as scarring, disfigurement, and/or disability that contribute to this belief. Here the therapist seeks to understand the distorted appraisals the client has made about the impact this will have on their life. Behavioural experiments can be used to test these beliefs. Here are some examples:

- "My scars are ugly and other people will be disgusted by them." Distributing a survey with photos of different people's scars, including their own, can help to test how others view them. Experiments in revealing scars, such as wearing clothing that displays them and assessing the reactions of others, can also be a useful test. The therapist can also wear something noticeable to see whether people react differently or look any longer to something else "out of the ordinary." This can help clients discover that people are curious, rather than disgusted, by scars and tend to only stare briefly or in passing.

- "I am physically fragile and will be hurt again." Some survivors who have physical injuries avoid exercise and other forms of physical contact for fear of being hurt. Medical professionals can be consulted to get a clear idea of the need for caution. Experiments involving increasing physical contact, for example the client and therapist hitting themselves with increasingly hard objects - from a feather to a pillow to a book - can test evidence of further harm.

- "I need to avoid all physical activity to limit my pain." Similarly, clients with chronic pain following a trauma may limit their physical activity further than is medically recommended. Experiments with testing different activities from gentle to moderate intensity and recording pain and fatigue before and after will help the client ascertain what is a manageable level of activity.

- "My life is pointless because I can't walk anymore." For clients who have been left with life-changing physical injuries, it is common to experience appraisals about life being less meaningful. This may result in a reduction in motivation to engage in previously valued activities. In this case, "reclaiming your life" activities focus on those that are still physically possible or equivalents and to test them out, rating levels of reward and pleasure before and afterwards. 
Table 3. Kim's behavioural experiment record form

\begin{tabular}{|c|c|c|c|c|}
\hline $\begin{array}{l}\text { Situation/trigger } \\
\text { Belief/emotion } \\
\text { Memory } \\
\text { Coping behaviour }\end{array}$ & $\begin{array}{l}\text { Prediction: } \\
\text { how likely }(0-100 \%)\end{array}$ & Experiment & $\begin{array}{l}\text { What actually happened? } \\
\text { Was your prediction correct? }\end{array}$ & $\begin{array}{l}\text { What did you learn? } \\
\text { How can you take this forward? }\end{array}$ \\
\hline $\begin{array}{l}\text { Seeing medical staff } \\
\text { Intrusion - nurse } \\
\text { injecting me } \\
\text { "The nurses are trying } \\
\text { to kill me" } \\
\text { "The staff are evil" } \\
\text { Avoid medical } \\
\text { appointments }\end{array}$ & $\begin{array}{l}\text { The staff will be hostile } \\
\text { to me }(80 \%) \\
\text { The nurses will be } \\
\text { mistreating the patients } \\
(100 \%)\end{array}$ & $\begin{array}{l}\text { Visit the ward and } \\
\text { observe the nurses } \\
\text { Arrange to speak to } \\
\text { the nurse who treated } \\
\text { me that night }\end{array}$ & $\begin{array}{l}\text { The nurses were happy to see me } \\
\text { They were being kind to the } \\
\text { patients } \\
\text { The nurse who treated me was } \\
\text { friendly; she said I was distressed } \\
\text { on the ward }\end{array}$ & $\begin{array}{l}\text { I was hallucinating because of the } \\
\text { medication; they weren't trying } \\
\text { to kill me } \\
\text { I was very likely treated with care } \\
\text { and respect } \\
\text { I can create a new image with } \\
\text { this info to update it }\end{array}$ \\
\hline
\end{tabular}

\section{Testing Beliefs about Memory-Focused Techniques and about Memories}

Some people with PTSD have beliefs about memoryfocused techniques used in CT-PTSD which limit their engagement. In CT-PTSD, problematic meanings associated with the trauma memory are accessed through a detailed recounting of the experience with in imagination (imaginal reliving) or by creating a written narrative of the experience. The worst moments in the memory (hotspots) are identified, and updated information is integrated into the trauma memory (for more information and training videos demonstrating these techniques, see www.oxcadatresources.com). Some clients fear they will be overwhelmed by the trauma memory if they engage in imaginal reliving or that they will experience extreme and long-lasting distress if they confront triggers to their memories. Early experiments with unhelpful coping behaviours such as thought suppression can also help clients start to rethink threatening beliefs about intrusive memories as unbearable or uncontrollable. Subsequently, behavioural experiments can be used to test these fears further, often by approaching or provoking memories in a less intense way (e.g., giving a brief account of the trauma, with eyes open and in the past tense, rather than the usual imaginal reliving technique involving a detailed account, with eyes closed and in the present tense) and collecting data on the experience, such as the intensity and duration of distress.

Clients may have negative expectations about what may happen in therapy (e.g., "I'll be locked in a hospital") or the reactions of the therapist (e.g., "if I disclose what happened, my therapist will be disgusted and reject me"). In these cases, treatment becomes an experiment in itself, and the client can be encouraged to make predictions and re-rate them as therapy progresses.

Other clients have concerns about the outcome of treatment. For example, people may fear that they will forget what really happened or lose the memory of a loved one who died if they recover from PTSD. This can be test- ed by regularly reviewing indicators of forgetting as treatment progresses.

Clients sometimes also have beliefs about the trauma memory itself. For example, some memories are misappraised or distorted or have elements which are constructed images rather than true memories (e.g., where a client did not witness the trauma but has an image of it). In these cases, finding out information to clarify what actually happened can be a helpful intervention.

Kim developed PTSD following an admission into intensive care where she experienced terrifying hallucinations that the staff were trying to kill her. Kim's therapist arranged for them to return to the unit where Kim had been treated. Kim predicted that the staff would be hostile to her on her return and that she would see evidence of them mistreating patients. However, on the visit, the staff remembered Kim and seemed pleased to see her. They told her that she had sometimes seemed distressed on the ward. Kim observed the staff interacting with patients and their families and observed that they were kind and respectful. This provided evidence towards Kim's new belief that she had been hallucinating on the ward and probably had not been mistreated. She used the image of the nurses treating the patients with kindness as a way of updating her frightening trauma memories. Kim's behavioural experiment record form is shown in Table 3.

\section{Experiments on Site Visits}

Derek's example of returning to the scene of a car accident and Kim's example of returning to the hospital where she had been treated illustrate some of the ways in which returning to the scene of a trauma can facilitate behavioural experiments. A "site visit" is an important part of treatment in CT-PTSD and is used to reconstruct the trauma memory, search for further information to address appraisals or gaps in the memory, practice "then versus now" trigger discrimination, and conduct behavioural experiments. It can be carried out in person or virtually and is usually accompanied by the therapist (for more information, see Murray et al. [2015]; for training videos, see www.oxcadatresources.com). 
For some clients, a site visit is a behavioural experiment in itself to test the prediction that something bad will happen if they return, such as another trauma or intense distress. Additional behavioural experiments are often useful during site visits to gather further information to test particular appraisals. Meetings with relevant parties such as medical or security staff who might be able to answer questions can often be pre-arranged. Other behavioural experiments may arise spontaneously while on the visit.

Anoushka returned to the block of flats where she had been assaulted by her ex-partner. She knew that he had moved away from the area, but still felt anxious that he might be there if she returned. She also feared that the visit would make her PTSD worse. During the visit, Anoushka noticed that the flats looked better cared for than when she had lived there. There was now CCTV by the door and security lights. Anoushka's partner was not there, and Anoushka felt calmer and safer than she had expected. While they were walking around the area, Anoushka bumped into a former neighbour and spoke to him briefly. The neighbour confirmed that Anoushka's ex-partner had not lived in the flats for a while and believed he had left the country. Anoushka's predictions about her partner being there and her PTSD getting worse did not occur.

Jessica and her therapist visited the crossing where she had crashed into a pedestrian on her moped. Both of them had been knocked out and injured; Jessica could not remember the impact itself and there were no other witnesses. Believing that she must have ridden through a red light, Jessica felt terribly guilty. To test her belief that Jessica had caused the accident, she and her therapist walked around the crossing, following the routes both she and the pedestrian had taken. When they went to cross, they noticed that there were no lights to tell pedestrians when to walk. Jessica realised that the crossing was not designed well and that the pedestrian could easily have crossed when the traffic light was green. This helped her feel less like it was all her fault and instead made her feel more angry at how badly the crossing had been designed. Afterwards she wrote to the council, asking them to improve it.

\section{How to Do Behavioural Experiments Well}

The examples described in this paper give a sample of the huge variety of behavioural experiments that can be used as part of CT-PTSD treatment. The basic process in designing an experiment is as follows: (1) The process or appraisal being targeted is identified and, in the case of beliefs, rated. (2) An experiment is designed collaboratively with the client to investigate or test the belief or process. (3) Predictions are identified. (4) The experiment is carried out. If appropriate, the beliefs and/or distress are re-rated during the experiment. (5) If possible, photographs or a video are taken of the experiment to capture the moment a belief is disconfirmed. (6) The results of the experiment are reviewed against the predictions. (7) Implications are discussed and the next steps are considered.
This process might sound laborious but can in fact be carried out quite quickly. A key element to success is to check that the experiment does indeed provide a test of the client's appraisal. Asking our clients ahead of the experiment, "What would it mean if your prediction isn't correct?" also helps us identify potential blocks to cognitive change. Clients have often encountered disconfirming evidence in the past but failed to change their belief (e.g., talking to a stranger without being attacked). This can be due to so-called "cognitive immunisation strategies" [e.g., Rief et al., 2015] such as disregarding evidence as an exception to the rule ("I was lucky that time") or discrediting a source of evidence ("that person was just being nice"). To guard against this eventuality, we need to make sure predictions are concrete, that the experiment provides the opportunity to test the beliefs, and that cognitive immunisation is minimised.

Behavioural experiment record forms can be used but are not essential. More important is that the you and the client are clear about what you are testing and that whatever the result, you clarify the point it proves by asking "... and what does that tell us about ...?" Experiments can be conceptualised as "no-lose" opportunities to gather data; all information is relevant. It is important to check for any cognitive immunisation strategies after the experiment and to encourage generalisation of learning. Experiments may need to be repeated in different situations to broaden their impact. Experiments can be planned in advance or done spontaneously and can take place during a therapy session or as homework. Often one experiment will lead on from another, and the therapist can use the momentum from a successful behavioural experiment to encourage another.

Sean was a military veteran who had experienced numerous traumas. He found busy public places very uncomfortable and was extremely watchful for potential assailants. He used numerous safety-seeking behaviours when out in public, including maintaining a distance from people, keeping his back to the wall, scanning people for possible weapons, and checking for exits. Sean agreed to go with his therapist to a busy shopping centre for a planned experiment to sit in a coffee shop for $10 \mathrm{~min}$ and chat without checking who was coming in and out of the door. During the 10min conversation, his therapist asked Sean to describe a recent holiday. Sean was surprised that he was able to keep his attention on the conversation and not check the door. His therapist asked whether Sean was agreeable to trying another experiment which involved him sitting with his back to the busy coffee shop. Sean's therapist took a photo of him smiling with his back to the coffee shop door. Sean was pleased with his progress and they continued with further behavioural experiments, including standing close to people in a queue, sitting in a busy place with their eyes closed, and going into a department store without planning an escape route. Having only planned to do one behavioural experiment, Sean managed to do six during a single therapy session and had numerous photos on his phone to demonstrate his progress. 


\section{Potential Pitfalls}

Not all behavioural experiments will go exactly to plan. Sometimes a client will experience intense emotions, dissociate, or have a memory intrusion while they are doing an experiment. As well as being unpleasant for the client and therapist, this will prevent meaningful learning, so the therapist will need to respond quickly to help the client manage their distress with "then versus now" discrimination and to help ground them if they are dissociated. If possible, the experiment should continue after a pause, but may need reconfiguring.

Occasionally there is an unexpected outcome to an experiment. In this case, the therapist can help the client think through the implications of the result and potentially try the experiment again, with adaptations if needed. All data are useful, so experiments should not be viewed as "win" or "lose," but as an opportunity to learn more.

Mo went back to a local park where he had been mugged to test his belief about being robbed again. While he was there, a fight broke out between a group of young people, and Mo became extremely frightened and wanted to leave immediately. Mo and his therapist retreated to a café near the park and observed what happened next. The police arrived quite quickly and the fight was broken up. No one appeared seriously hurt. Once Mo had calmed down, his therapist asked him to reflect on the differences between his trauma and the fight he had witnessed. Mo recognised that he had not been in danger in this situation as the fight seemed to be pre-arranged between two gangs. Although he had felt scared, Mo had not panicked or frozen as he had at the time of the trauma. Also, help had arrived quickly in the form of the police. Mo felt that it would be safe to return to the park, at least during daytime hours, but reflected that there might be a problem with antisocial behaviour in the area. He and his therapist agreed a further experiment: to contact the police about security in the park and to find out whether such incidents were common or rare.

As discussed in the previous section, another common pitfall is where results of an experiment are disregarded. In these situations, we need to return to the design of the experiment and discuss with our clients how we can truly test their belief. In some cases, the experiment should be repeated in a different situation or with different parameters. For example, if a client discredits the results of a survey as the respondents being biased in some way, we can explore this belief and discuss how to gather more accurate data.

\section{Behavioural Experiments in Remotely Delivered Therapy}

The emphasis throughout this article has been on carrying out behavioural experiments during therapy sessions and leaving the therapy room together. However, with the development of effective remotely delivered treatments, we may not always be in the same physical place as our client. At the time of writing, the global COVID-19 pandemic prevents us from delivering face-toface therapy and conducting some experiments.
Some creativity is required, but it is certainly still possible to design effective behavioural experiments when working remotely. In-session behavioural experiments conducted in the therapy room can still be used when we are working over the phone or video conferencing. Clients can be outside during sessions doing experiments or site visits and talking to us on the phone at the same time. Supportive friends or family can be recruited to accompany and support clients on behavioural experiments.

Virtual tools are also important. We can conduct surveys, contact experts, and do internet research together in session, sharing screen while video conferencing in order to review results. Virtual site visits using Google Street View allow us to revisit the scene of the trauma where it is not possible in real life.

\section{Concluding Remarks}

Behavioural experiments can be a powerful tool in treating PTSD as well as other psychological disorders. As PTSD very often manifests with features typical of other disorders, such as obsessive-compulsive or panic disorder, you can often find that behavioural experiments designed for other conditions are equally relevant to aspects of treating PTSD. They can be used at all stages of treatment in CT-PTSD to demonstrate the effects of coping strategies, address appraisals of various types, and overcome barriers, such as blocking beliefs which are standing in the way of treatment. Effective experiments are individualised, targeted, and memorable. Some behavioural experiments will need careful planning, but the technique is also highly flexible and can easily be spontaneously integrated into clinical sessions to gather experiential evidence and to maximise learning.

\section{Acknowledgement}

The authors thank Prof. Anke Ehlers for reviewing the manuscript.

\section{Statement of Ethics}

Ethics approval was not required for this paper. The cases described are amalgamations of several different patients and are fully anonymised.

\section{Conflict of Interest Statement}

The authors have no conflicts of interest to declare. 


\section{Funding Sources}

H. Murray is funded by the Wellcome Trust and the NIHR Oxford Health Biomedical Research Centre. The views expressed are those of the authors and not necessarily those of the NHS, the NIHR, or the Department of Health.

\section{Author Contributions}

H. Murray and S. El-Leithy created the concept, structure, and content of the paper jointly. H. Murray wrote an initial draft of the paper, which S. El-Leithy commented on.

\section{References}

Becker CB, Zayfert C, Anderson E. A survey of psychologists' attitudes towards and utilization of exposure therapy for PTSD. Behav Res Ther. 2004 Mar;42(3):277-92.

Bennett-Levy J, Westbrook D, Fennell M, Cooper M, Rouf K, Hackmann A. Behavioural experiments: historical and conceptual underpinnings. In: Bennett-Levy J, Butler G, Fennell M, Hackmann A, Mueller M, Westbrook D, editors. Oxford guide to behavioural experiments in cognitive therapy. Oxford, UK: Oxford University Press; 2004. p. 1-20.

Clark DM. A cognitive perspective on social phobia. In: Crozier WR, Alden LE, editors. The essential handbook of social anxiety for clinicians. Chichester, UK: John Wiley \& Sons; 2005. p. 193-218.

Craske MG, Treanor M, Conway CC, Zbozinek T, Vervliet B. Maximizing exposure therapy: an inhibitory learning approach. Behav Res Ther. 2014 Jul;58:10-23.

Ehlers A. Posttraumatische Belastungsstörung. Fortschritte der Psychotherapie. Göttingen: Hogrefe; 1999.

Ehlers A, Clark DM. A cognitive model of posttraumatic stress disorder. Behav Res Ther. 2000 Apr;38(4):319-45.
Ehlers A, Clark DM, Hackmann A, McManus F, Fennell M. Cognitive therapy for post-traumatic stress disorder: development and evaluation. Behav Res Ther. 2005 Apr;43(4):41331.

Ehlers A, Clark DM, Hackmann A, McManus F, Fennell M, Herbert C, et al. A randomized controlled trial of cognitive therapy, a selfhelp booklet, and repeated assessments as early interventions for posttraumatic stress disorder. Arch Gen Psychiatry. 2003 Oct;60(10): 1024-32.

Ehlers A, Grey N, Wild J, Stott R, Liness S, Deale A, et al. Implementation of cognitive therapy for PTSD in routine clinical care: effectiveness and moderators of outcome in a consecutive sample. Behav Res Ther. 2013 Nov;51(11): 742-52.

Ehlers A, Hackmann A, Grey N, Wild J, Liness S, Albert I, et al. A randomized controlled trial of 7-day intensive and standard weekly cognitive therapy for PTSD and emotion-focused supportive therapy. Am J Psychiatry. 2014 Mar;171(3):294-304.
Engelkamp J. Memory for actions. Hove, UK Psychology Press/Taylor \& Francis; 1998.

Kube T, Berg M, Kleim B, Herzog P. Rethinking post-traumatic stress disorder - a predictive processing perspective. Neurosci Biobehav Rev. 2020 Jun;113:448-60.

Kube T, Rozenkrantz L. When beliefs face reality: an integrative review of belief updating in mental health and illness. Perspect Psychol Sci. 2020 doi: 10.1177/1745691620931496 [Epub ahead of print].

Murray H. Evaluation of a trauma-focused CBT training programme for IAPT services. Behav Cogn Psychother. 2017 Sep;45(5):467-82.

Murray H, Merritt C, Grey N. Returning to the scene of the trauma in PTSD treatment - why, how and when? Cogn Behav Therap. 2015; 8:e28.

Rief W, Glombiewski JA, Gollwitzer M, Schubö A, Schwarting R, Thorwart A. Expectancies as core features of mental disorders. Curr Opin Psychiatry. 2015 Sep;28(5):378-85.

Wegner DM, Schneider DJ, Carter SR 3rd, White TL. Paradoxical effects of thought suppression. J Pers Soc Psychol. 1987 Jul;53(1):5-13. 